http://dx.doi.org/10.30681/23588403v11i012215225

\title{
NOTÍCIA ATUAL DA CRÍTICA LITERÁRIA DE MACHADO DE ASSIS
}

\author{
Data de recebimento: 19/07/2017
}

Aceite:23/09/2017

Tiago leite COSTA (PUC-RJ) ${ }^{1}$

\begin{abstract}
Resumo: O artigo apresenta uma reflexão panorâmica sobre a atividade crítica de Machado de Assis, com o intuito de discutir seu papel na tradição do pensamento ensaístico nacional. A hipótese do texto é a de que Machado de Assis foi um interprete extemporâneo, que produziu um conjunto ímpar de reflexões cuja originalidade permanece fonte para inúmeros desdobramentos nos âmbitos dos estudos literários e dos estudos de literatura brasileira.
\end{abstract}

Palavras-chave: Machado de Assis. Literatura brasileira. Crítica literária.

Abstract: The article presents a panoramic reflection on the critical activity of Machado de Assis, with the purpose of discussing its role in the tradition of the national essayist thought. The hypothesis of this paper is that Machado de Assis was an extemporaneous interpreter, who produced a set of reflections whose originality remains source for innumerable insights in the fields of literary studies and studies of Brazilian literature.

Keywords: Machado de Assis. Brasilian literature. Literary criticism

\begin{abstract}
“(...) perguntarei se o Hamlet, o Otelo, o Júlio Cesar, a Julieta e Romeu têm alguma coisa com a história inglesa nem com o território britânico, e se, entretanto, Shakespeare não é, além de um gênio universal, um poeta essencialmente inglês. Não há dúvida que uma literatura, sobretudo uma literatura nascente, deve principalmente alimentar-se dos assuntos que lhe oferece a sua região; mas não estabeleçamos doutrinas tão absolutas que a empobreçam. $\mathrm{O}$ que se deve exigir de um escritor antes de tudo, é certo sentimento íntimo, que o torne homem do seu tempo e do seu país, ainda quando trate de assuntos remotos no tempo e no espaço." (ASSIS, Notícia atual da literatura brasileira.1942, p.139).
\end{abstract}

A passagem acima é provavelmente a mais conhecida e reproduzida da obra crítica de Machado de Assis. Como se sabe, trata-se de um excerto de Noticia da atual literatura brasileira. Instinto de nacionalidade, ensaio que até hoje causa espanto pela extemporaneidade e precisão com que traçava o diagnóstico da nascente literatura brasileira.

\footnotetext{
${ }^{1}$ Tiago Leite Costa é formado é Doutor em Letras/Literatura pela PUC-RJ/Brasil.

Email: tiagoleite79@gmail.com
} 
Não à toa, continua frequente sua evocação sempre que a censura do nacionalismo artístico renasce das cinzas.

O tema da identidade nacional não desapareceu do campo dos estudos literários, mas é inegável que o assunto cedeu terreno para a reflexão sobre outros dilemas culturais e estéticos. Esta mudança geralmente tem se refletido na demanda por teorias capazes de interagir com novos mecanismos de representação, voltados para novas concepções de identidade. De preferência, teorias capazes de forjar uma crítica literária ágil o suficiente para lidar com o cipoal de formas digitais e de novos autores, impossíveis de serem explorados unicamente com os mapas teóricos do século passado.

O ideal, no entanto, seria que essa renovação não se fizesse alheia à visão histórica. Por mais desconfiados que estejamos das velhas premissas ontológicas da historiografia e de seus determinismos socioculturais, nenhuma mudança original e consistente se faz sem um cuidadoso olhar para o retrovisor. Até porque a consciência do caráter construído da História não a torna descartável. Antes, desafia os pesquisadores a produzirem novas versões capazes de desestabilizar a interpretação oficial do passado e, com isso, ressignificar nossas certezas presentes.

Nesse sentido, uma das tendências mais enriquecedoras dos estudos de literatura brasileira tem sido a da elaboração de novas genealogias da nossa tradição literária. A redescrição da história da literatura, calcada em abordagens interdisciplinares, tem produzido versões alternativas de autores consagrados e recuperado nomes ignorados pela historiografia literária.

Há algumas décadas esse trabalho vem sendo realizado em inúmeras frentes no que concerne à reinterpretação do nosso cânone poético e romanesco. Porém, é relativamente exíguo o número de pesquisas que apontam para novos olhares sobre a tradição crítica ensaística nacional. Algo compreensível, tendo em vista a transitoriedade inevitável das hipóteses teóricas do campo das artes e da cultura. Transitoriedade pela qual a literatura de ficção criativa se reinventa continuamente, mas que relega muitos pressupostos conceituais ao ostracismo.

Isso não significa, é claro, que a crítica literária esteja fadada ao mofo. Os críticos verdadeiramente inventivos podem perfeitamente ter suas análises reinterpretadas e servirem como agentes da desconstrução dos juízos históricos cristalizados, enriquecendo os dilemas contemporâneos. 
Assim, diante das incansáveis demandas para a renovação do pensamento crítico nacional, penso que é de suma importância investigações que se disponham a conceber novas cronologias para o gênero no Brasil, erguendo novas pontes teóricas entre a crítica moderna e a contemporânea. A hipótese do presente texto é a de que a obra ensaística de Machado de Assis é uma peça relevante nessa arquitetura.

Machado exerceu a crítica literária antes de se tornar romancista. Em diversos artigos e ensaios escritos para jornais, entre as décadas de 1850-70, o leitor encontra um crítico engajado, não apenas na avaliação pontual do que se produzia na época, mas principalmente na tarefa de indicar caminhos para a formação de autores e leitores brasileiros.

Embora conhecidos, em poucas ocasiões esses ensaios foram analisados e concebidos como um conjunto autônomo, caraterizado por traços específicos. Existem relativamente poucos trabalhos de fôlego dedicados à sistematização das ideias apresentadas nesses textos, de modo a interpretá-los como uma unidade com suas coerências e incongruências.

A constante renovação dos estudos sobre a obra ficcional do autor não parece ser acompanhada de pesquisas sobre a singularidade de sua obra crítica. Esta, geralmente, é utilizada como apoio para analise de seus romances ou para a ilustração de discussões pontuais sobre literatura brasileira. Todavia, raramente o percurso inverso é traçado, isto é, raramente dispõe-se do repertório analítico sobre a ficção de Machado e sobre crítica literária nacional para entender seus ensaios.

Não obstante, é possível depreender uma série de atributos peculiares às ideias e à linguagem de seus textos críticos, que, examinados em suas particularidades discursivas, podem enriquecer a compreensão do pensamento de Machado de Assis sobre a literatura e sobre a composição de seus romances, bem como auxiliar no entendimento do debate literário do século XIX.

Não tenho a pretensão aqui de preencher esta lacuna dos estudos machadianos em um breve artigo. Mas se de alguma forma contribuirmos para aguçar o interesse de pesquisadores na renovação dos estudos sobre a obra ensaística de Machado o objetivo do texto terá sido comprido.

Assim, poderíamos começar afirmando que, historicamente, Machado foi relegado a coadjuvante no cânone ensaístico brasileiro porque sua obra crítica, além de circunscrita à dita primeira fase do autor, não pode ser comparada em importância ao papel único de sua ficção na história da nossa literatura. Ainda assim, críticos de primeira linha sempre destacaram a 
qualidade singular desses textos. Para que, de fato, uma nova intepretação da obra crítica de Machado seja possível seria preciso primeiro revisitar as análises tradicionais destes ensaios, como as de Mário Alencar (1942), Tristão de Ataíde (1986), Afrânio Coutinho (1968), José Aderaldo Castello (2013), Marlene de Castro Correia (2015)² e José Guilherme Merquior. Este último, por exemplo, chega a afirmar que:

Machado não foi só um criador crítico, foi também o mais elevado e capaz praticante de crítica per se, da crítica enquanto tribuna estética, e enquanto análise e julgamento de obras literárias, que o Brasil possui no século passado. Os seus principais ensaios: "Instinto de Nacionalidade" (1873), a apreciação de "O Primo Basílio" (1878), “A nova geração" (1879) - não têm o que os sobrepuje na produção crítica contemporânea, sem excluir os melhores estudos de Romero, Veríssimo ou mesmo Araripe Jr. (1977, p.161).

Em seguida, seria importante contrastar a fortuna crítica tradicional sobre a obra ensaística de Machado com leituras renovadoras realizadas por estudiosos como José Luiz Jobim (2010), Paulo Franchetti (2007), Edison Bariani (2007), João César de Castro Rocha (2013) e Gustavo Bernardo (2013).

Cruzando as referências mencionadas acima, é possível dizer que há uma sutil correlação entre o contexto em que Machado de Assis produziu seus principais ensaios de crítica literária e o atual cenário das discussões sobre a literatura brasileira. Como se sabe, então se anunciava a decadência do Romantismo junto aos presságios da nova literatura, liderada pelo Realismo. Em geral, Machado era contrário tanto à obsessão romântica pela "cor local"3 quanto à "poética de inventário" realista. No entanto, defendia que o fundamental era distinguir méritos e limitações de ambos os projetos. Para além dos modismos, estava interessado em compreender a intrincada autonomia do fenômeno estético.

Não falta quem conjugue o ideal poético e o ideal político, e faça de ambos um só intuito, a saber, a nova musa terá que cantar o Estado republicano. Não é isto, porém, uma definição, nem implica um corpo de doutrina

\footnotetext{
${ }^{2}$ Todas as datas fazem referem às edições indicadas na bibliografia e não ao ano de produção dos textos.

${ }^{3}$ Ressalte-se que Machado apresenta algumas oscilações de juízo sobre as concepções românticas. Essa alternância pode ser observada no trajeto que vai de $O$ presente, o passado e o futuro da literatura brasileira (1858) à Instinto de nacionalidade (1873), passando pela resenha de Iracema (1866) de José de Alencar. A crítica de 1873 não tem respaldo na amena e estratégica postura dos textos de 1858 e 1866.
} 
literária (...). Essa aspiração ao reinado da justiça (que é afinal uma simples transcrição de Proudhon) não pode ser uma doutrina literária; é uma aspiração e nada mais. (...). Mas entre uma aspiração social e um conceito estético vai diferença; o que se precisa é uma definição estética. (A nova geração, 1942, p.191-194)

Confrontada com a intepretação sociológica da literatura em voga na época (CORREIA, 2015), essa era uma posição anômala para o contexto brasileiro. Para não dizer ambígua, uma vez que desatava cabrestos políticos (românticos ou realistas), em nome de difusas "Regras da arte", "Leis poéticas", "Leis do belo", frequentemente mencionadas nos ensaios.

É certo, porém, que o que Machado entendia como "Princípios da arte" não era nenhum imobilismo classicista. Pelo contrário, lamentava que alguns jovens autores ainda cedessem a expedientes mecânicos, nos quais persistiam "as epopeias, os Prometeus, os gigantes, as Babeis, todo esse vocabulário de palavras grandes destinadas a preencher o vácuo das ideias justas" (ASSIS, A nova geração, 1942, p.250).

Talvez, então, como hipótese provisória, pudéssemos dizer que Machado inclinavase a uma espécie de "suspensão dialética" entre o eterno-transitório, o universal-local, socialindividual e a técnica-inspiração. Desta perspectiva é que ele censurava tanto os arroubos subjetivos dos byronianos, como a grandiloquência condoreira. Também era deste ângulo que recriminava a crueza descritiva dos realistas, aconselhando aos mais jovens: "Voltemos os olhos para a realidade, mas excluamos o realismo; assim não sacrificamos a verdade estética". (ASSIS, O primo Basílio, 1942, p.185).

O problema das diretrizes da literatura nacional não se extinguiu com o fim do século XIX, mas se metamorfoseou em função dos diferentes contextos políticos e culturais do século XX. Hoje, no século XXI, a questão pode soar obsoleta. Curiosamente, porém, o declínio do nacionalismo literário aparece mais uma vez cercado de questionamentos sobre a crítica literária realizada no Brasil Como se o esvaziamento do projeto nacional moderno tivesse deixado um vácuo de referência para o pensamento crítico. Segundo Alcir Pécora:

$\mathrm{Na}$ ideia de "instinto de nacionalidade", de Machado, a centralidade da literatura no debate nacional estava posta com toda a energia. Agora estamos do outro lado do parafuso, numa espécie de "entre-lugar" -; um "entrelugar" porque o nacional já não alcança obter nenhuma representação importante e porque o internacional tampouco dá à forma literária relevância 
maior do que a da expressão pessoal ou da representação de comunidades restritas, de grupos de "subjetividades expandidas" e, paradoxalmente, de "eus mínimos" (...). Quando Machado escreve esse ensaio, a literatura parecia ser o lugar justo para pensar o país e qualquer outra coisa que dissesse respeito à vida pessoal e pública. Hoje o âmbito se reduziu à senha de pertença a pequenos grupos. Na rede social é assim, mas na literatura que fica lançando piscadinhas para o leitor também. (2015)

Evidentemente, existem diferenças abismais entre os dois contextos. É incomparável o protagonismo da literatura no debate cultural do século XIX com sua atuação quase de resistência no cenário atual. Mas não deixa de ser interessante perceber a semelhança de alguns traços de ambos os debates.

Por exemplo, inúmeras vezes, Machado atacou a parcialidade que impedia a evolução do exercício crítico no Brasil. Em $O$ ideal do crítico, por exemplo, afirmava que: "A profissão do crítico deve ser uma luta constante contra todas essas dependências pessoais, que desautoram seus juízos, sem deixar de perverter a opinião. Para que a crítica seja mestra, é preciso que seja imparcial, - armada contra a insuficiência dos seus amigos, solícita pelo mérito dos seus adversários" (ASSIS, O ideal do crítico, 1942, p.11).

Realmente, parece que o tema não envelhece. Porém, mais do que isso, o que a comparação das duas passagens indica é que frente à ausência de referências hegemônicas, as filiações a comunidades literárias e a disputa entre as mesmas estabelecem parâmetros medíocres para a inovação crítica e criativa da literatura.

Outra analogia exemplar pode ser estabelecida se observarmos que, como correu na década de 1870 e 1970, mais uma vez, o desgaste da estética nacionalista é ensejo para mais um renascimento do "realismo literário". Atualmente os críticos diagnosticam um "novo-novo realismo" da literatura brasileira contemporânea (o "novo realismo" seria o de 1970), que almejaria “ser simultaneamente 'engajada' sem necessariamente subscrever nenhum programa político". (SCHOLLHAMMER, 2009, p.54).

Há de se perguntar o que significa esse incessante retorno do realismo. Provavelmente há mais de uma explicação para o fenômeno. Contudo, não perece exagerado afirmar que os diferentes realismos literários partilham a crença de que é preciso revelar a realidade nua e crua para que haja a possibilidade de superação de seus aspectos negativos. Se isso for verdade, o que queria dizer Machado de Assis no ensaio “A Nova Geração” quando afirma que "a realidade é boa, o realismo é que não presta.” (ASSIS, 1942, p.203)?

\footnotetext{
${ }^{4}$ Sobre o tema, ver também Pelegrini (2012), Tonani (2012), entre outros.
} 
Segundo Gustavo Bernardo, nessa passagem, Machado percebe o que discurso realista afirma nas entrelinhas: "a realidade é ruim, decerto, mas eu sou bom porque eu e só eu consigo perceber como a realidade é ruim":

"Logo, o realista considera a realidade como má para então poder se considerar como bom, ou seja, como o único capacitado a ver a realidade como má. Não é mera coincidência qualquer semelhança da estrutura do argumento com a estrutura do ressentimento tantas vezes denunciada por Nietzsche. O realista é, na visão machadiana, antes de tudo um ressentido, recusando qualquer perspectiva que não seja a sua ou que não o coloque como centro do mundo e da verdade. Em consequência, o realista também é antes de tudo um dogmático, usando sua própria condição de realista autonomeado para desqualificar qualquer pensamento divergente" (2013, p.86).

Se concordarmos com o raciocínio de Gustavo Bernardo, seria interessante pensar como a crítica machadiana poderia elucidar os sucessivos retornos do realismo na literatura brasileira. Não se trata de fazer um transplante artificial da discussão do século XIX para o atual debate literário nacional. Quando menciono certas analogias, faço atento aos limites históricos e sem nenhuma intenção de construir um panegírico ao crítico Machado de Assis.

É fundamental não deixar que a intempestividade do autor contamine o nosso exame, idealizando uma organicidade absoluta em suas posições ou, o que é pior, achatando a perspectiva histórica da análise. Desse modo, é preciso avaliar não apenas o que há de extemporâneo em suas ideias, mas também o que há de anacrônico.

Assim, para alguns estudiosos, os ensaios podem revelar um crítico normativo e conservador. Esta, por exemplo, é a opinião de João César de Castro Rocha (2013), para quem os artigos sobre $O$ Primo Basílio representam o ocaso da primeira fase machadiana. $\mathrm{O}$ último suspiro do "Machadinho", conforme o célebre epíteto de Augusto Meyer (1958).

(...) O Machadinho de 1878, isto é, o leitor de O primo Basílio, certamente condenaria o Machado de 1880, ou seja, o autor de Memórias póstumas de Brás Cubas. Para o crítico moralista de 1878, as aventuras de Brás Cubas pareceriam desnecessariamente eróticas; o móvel de suas ações pouco definido; sobretudo, o crítico normativo de 1878 rejeitaria a falta de verossimilhança de um defunto narrador (...) a fim de produzir a revolução Brás Cubas, o autor Machado precisou despedir-se de Machadinho leitor de $O$ primo Basílio. A crítica machadiana não tem sido capaz de dizê-lo com clareza necessária porque parte do pressuposto otimista de que coincidem o leitor do romance de Eça e o autor de Memórias Póstumas. (ROCHA, 2013, p. 122-123). 
Desta perspectiva, é de se supor que o trabalho crítico de Machado teria pouco a acrescentar no esclarecimento dos dilemas atuais do pensamento crítico nacional. Com efeito, não é raro encontrar nos ensaios posturas decisivamente conservadoras em relação às normas do romance, que não fazem jus a linguagem revolucionária da chamada segunda fase de 1880 em diante.

Finalmente, quem é o Machado crítico literário? Suas concepções sobre a criação literária e sobre o cenário da literatura brasileira são intempestivas ou simplesmente ultrapassadas? Creio que esse problema ainda não foi suficientemente debatido. No entanto, me parece que o exame e a comparação exaustiva da bibliografia sobre os ensaios (o que não foi possível no espaço do artigo) podem revelar pontos de vista inventivos sobre o embate de forças do meio literário nacional, ainda que tais pontos não sejam a nota dominante em toda a crítica machadiana.

Segundo Antonio Candido (2004), a unanimidade entorno do nome de Machado de Assis está ligada a algo que diferenciava a sua literatura daquela praticada em sua época. Alguma coisa que, ao mesmo tempo, foi reconhecida pelos seus contemporâneos como singular, e que também se manteve significativa para as gerações de leitores do século XX, que se formaram lendo Kafka, Joyce, Borges etc.

Podemos dizer o mesmo de seus ensaios? Sua literatura crítica teria algo da força dos seus romances e permaneceria fonte de insights para nós leitores do século XXI?

Essas foram algumas das perguntas que moveram este artigo e que continuam ainda insuficientemente respondidas. Para esclarecê-las é preciso que os estudiosos da obra de Machado releiam esses textos com novas lentes, e não apenas com as que tradicionalmente vêm sendo usadas para entender sua obra ficcional. Acima de tudo, seria necessário colocar em contato a fortuna crítica machadiana com as novas perspectivas da crítica literária acerca da literatura brasileira de ontem e de hoje.

\section{Referências:}

ALENCAR, Mário de. Prefácio da edição de 1910. In: ASSIS, J. Crítica Litterária. Rio de Janeiro: W. M. Jackson, 1942.

ASSIS, Joaquim Maria Machado de. Crítica Litterária. W. M. Jackson, 1942.

Obra completa. 3 volumes. Rio de Janeiro: Nova Aguilar, 1986.

ARARIPE JR., Tristão de Alencar. Machado de Assis. In: Revista Brasileira. Rio de 
Janeiro. Ano $\quad$ I, $1995 . \quad$ Disponível

http://docvirt.com/docreader.net/DocReader.aspx ?bib=BibObPub\&PagFis=8323

Acesso: 10/2016.

ATAÍDE, Tristão de. Machado de Assis, o crítico. In: ASSIS, Machado de. Obra completa. Vol. 3. Rio de Janeiro: Nova Aguilar, 1986.

BARIANI, Edson. O silêncio do desdém: o crítico Machado de Assis. In: ÍCONE -

Revista de Letras, São Luís de Montes Belos, v. 1, p. 85-92, dez. 2007. Disponível em:

http://www.slmb.ueg.br/iconeletras/artigos/edison.pdf .Acesso: 10/2016

BERNARDO, Gustavo. O problema do realismo em Machado de Assis. Rio de Janeiro: Rocco, 2015.

BOSI, Alfredo. Machado de Assis - o enigma do olhar. São Paulo: Ática, 1999.

CALDWELL, Helen. O Otelo brasileiro de Machado de Assis. São Paulo: Ateliê

Editorial, 2002.

CANDIDO, Antonio. Vários Escritos. Rio de Janeiro: Ouro sobre Azul, 2004.

CORREIA, Marlene Castro. A atualidade da crítica de Machado de Assis. In:

Littera. Rio de Janeiro, Grifo, ano 1, n. 2, p. 3-21, maio-ago. 1971. Disponível em: http://www.scielo.br/scielo.php?script=sci_arttext\&pid=S1983-68212015000200003. Acesso: $10 / 2016$

CASTELlO. José Aderaldo Castello. Ideário crítico de Machado de Assis (breve contribuição para o estudo de sua obra).In: Machado de Assis em linha. Rio de Janeiro. v. 6, n. $12, \quad$ p. 01-14, dezembro 2013. Disponível em: http://www.scielo.br/pdf/mael/v6n12/a02v6n12.pdf Acesso: 10/2016 COUTINHO, Afrânio. Crítica e poética. Rio de Janeiro: Acadêmica, 1968.

EULÁLIO, Alexandre. Escritos. Campinas; São Paulo: Editora da Unicamp; Editora Unesp, 1992.

FRANCHETTI, Paulo. O primo Basílio e a batalha do Realismo no Brasil. In: Estudos de literatura brasileira e portuguesa. São Paulo: Ateliê Editorial, 2007.

GLEDSON, John. Machado de Assis: impostura e realismo: uma reinterpretação de Dom Casmurro. São Paulo: Companhia das Letras 1991.

GUIMARÃES, Hélio de Seixas. Os leitores de Machado de Assis: o romance machadiano e o público de literatura no século 19. São Paulo: Edusp/ Nankin, 2004.

JOBIM, José Luís. Machado de Assis: o crítico como romancista. In: Machado de Assis em linha. Rio de Janeiro: ano 3, número 5, junho 2010. 
Disponível em:

http://machadodeassis.net/download/numero05/num05artigo07.pdf. Acesso:

$10 / 2016$

LIMA, Luiz Costa. Letras à míngua. Folha de São Paulo, São Paulo, 27 ago. 2006.

Disponível em: http://www1.folha.uol.com.br/fsp/mais/fs2708200608.htm.

Acesso: 10/2016.

MERQUIOR, José Guilherme. De Anchieta a Euclides: breve história da literatura brasileira. Rio de Janeiro: J. Olympio, 1979.

MEYER, Augusto. De Machadinho a Brás Cubas. Teresa: revista de literatura brasileira. São Paulo. V.6. 2006. Disponível em:

http://docvirt.com/docreader.net/DocReader.aspx?bib=revistateresausp\&pagfis=1735\&pesq= Acesso: 10/2016

PÉCORA, Alcir. Apolítica, uma literatura de segundo grau. In: Sibila: revista de poesia e crítica literária. São Paulo, 2015. Disponível em:

http://sibila.com.br/critica/apolitica-uma-literatura-de-segundo-grau/11557

PEREIRA, Cilene Margarete. Os prefácios dos romances iniciais e o método de composição de Machado de Assis. In: Crítica Cultural. v.8 , n.1. p. 85-98. Santa Catarina: UNISUL, 2013.

Disponível

em:

file:///C:/Users/tiago\%20costa/Documents/concursos/Prefácios\%20de\%20Machado.pdf

Acesso: 10/2016.

PEREIRA, Lúcia Miguel. Machado de Assis: (estudo crítico e biográfico). Belo

Horizonte: Itatiaia ; São Paulo: Ed. da Universidade de São Paulo, 1988.

PELLEGRINI, Tânia. Realismo: modos de usar. In: Scielo: Estud. Lit. Bras. Contemp.

no.39 Brasília Jan./June 2012. Disponível em:

http://www.scielo.br/scielo.php?script=sci arttext\&pid=S2316-40182012000100001 Acesso: $10 / 2016$

ROCHA, João Cezar de Castro. Machado de Assis: por uma poética da emulação.

Rio de Janeiro: Civilização Brasileira, 2013.

ROMERO, S. Machado de Assis: estudo comparativo de literatura brasileira.

Campinas: Editora da Unicamp, 1992.

SANTIAGO, Silviano. Uma Literatura nos trópicos. Rio de Janeiro: Rocco, 2000. 
SCHWARZ, Roberto. Ao vencedor as batatas: forma literária e processo social nos inícios do romance brasileiro. São Paulo: Duas Cidades, 1988.

, Um mestre na periferia do capitalismo: Machado de Assis. São Paulo:

Duas Cidades: Ed. 34, 1990.

SCHOLLHAMMER, Karl Eric. Ficção brasileira contemporânea. Rio de Janeiro:

Civilização brasileira. 2009.

SÜSSEKIND, Flora. Crítica como papel de bala O Globo. Rio de Janeiro, 24 de abril de 2010. Disponível em: http://blogs.oglobo.globo.com/prosa/post/a-critica-como-papel-de-bala286122.html. Acesso: 10/2016.

TONANI, Paulo Roberto. A volta da realidade das margens. In: Scielo. Estud. Lit.

Bras. Contemp. no.39 Brasília Jan./Jun. 2012. Disponível em: http://www.scielo.br/scielo.php?script=sci_arttext\&pid=S2316-

40182012000100004\&lng=en\&nrm=iso\&tlng=pt Acesso: 10/2016

VENTURA, Roberto. Estilo tropical: história cultural e polêmicas literárias no

Brasil - 1870-1914. São Paulo: Companhia das Letras, 1991.

VERÍSSIMO, José. Estudos de literatura brasileira. Belo Horizonte: Itatiaia, 1979. 